\title{
COMMENTARY
}

\section{Improving outcome in out-of-hospital cardiac arrest: impact of bystander cardiopulmonary resuscitation and prehospital physician care}

\author{
Robert JH Jackson ${ }^{1 *}$ and Jerry P Nolan² \\ See related research by Yasunaga et al., http://ccforum.com/content/14/6/R199
}

\begin{abstract}
Evidence for the impact of prehospital, physiciandelivered advanced cardiac life support (ACLS) on survival from out-of-hospital cardiac arrest is conflicting. The prospective observational study by Yasunaga and co-workers demonstrates an improved survival at 1 month associated with prehospital physician-delivered ACLS over emergency life-saving technician-delivered ACLS. These effects are additive to the survival benefit seen with bystander-initiated cardiopulmonary resuscitation (BCPR) compared with no BCPR. The present commentary places these findings in the context of the existing literature and discusses some of the unresolved controversies.
\end{abstract}

Yasunaga and co-workers have used the nationwide registry of out-of-hospital cardiac arrest patients in Japan to evaluate prospectively two key components of the chain of survival: early cardiopulmonary resuscitation (CPR) and early advanced cardiac life support (ACLS) [1]. Following out-of-hospital cardiac arrest, it is generally acknowledged that bystander CPR increases long-term survival rates by two to three times [2] and that each minute of delay before defibrillation reduces the probability of survival to discharge by 10 to $12 \%$ [3]. Whether or not ACLS interventions (such as drugs and tracheal intubation) affect outcome is much more contentious [4].

The study compares the combined impact of bystanderinitiated cardiopulmonary resuscitation (BCPR) and physician-delivered ACLS - with BCPR emergency lifesaving technician (ELST)-delivered ACLS. The potential interventions provided by physicians, but not the ELSTs,

*Correspondence: robjjackson@doctors.org.uk

'Intensive Care Medicine, Royal United Hospital NHS Trust, Bath BA1 3NG, UK Full list of author information is available at the end of the article included: tracheal intubation, central venous catheterisation, and injection of lidocaine, atropine and vasoactive, anaesthetic and fibrinolytic drugs. Yasunaga and coworkers have compared the outcomes from four groups of patients following witnessed cardiac arrest: those who received ELST-delivered ACLS without (Group A) and with (Group B) BCPR, and those who received physiciandelivered ACLS without (Group C) and with (Group D) BCPR.

Consistent with previous studies, bystander CPR improved survival rates at 1 month by approximately $50 \%$ in both those patients receiving ELST-delivered ACLS and those who received physician-delivered ACLS.

Previous studies have failed to show a survival benefit following implementation of ACLS in the out-of-hospital setting [4]. This study has demonstrated an increase in survival in all patient groups associated with the addition of physician-delivered ACLS. Worryingly, however, in the patients who did not receive bystander CPR, this increase in survival was due largely to an increase in patients surviving with severe neurological injury (cerebral performance category 3 or 4). It is perhaps no surprise that if return of spontaneous circulation is achieved after a long time without effective CPR then anoxic brain injury will inevitably have occurred, resulting in poor neurological outcome.

Only a small proportion of patients achieved a good neurological outcome (cerebral performance category 1 at 1 month): Group A 1.9\%, Group B 4.1\%, Group C 2.7\% and Group D 6.4\%. This implies that the most important determinant of survival with good neurological outcome is early initiation of bystander CPR and not rapid access to physician-delivered ACLS, although the combined approach did generate the most neurologically intact survivors.

Since this was an observational study, it is possible that hidden confounders may have affected the results. The most important, as suggested by the authors, is that postresuscitation care was likely to have been different in patients who received physician ACLS compared with 
those receiving ELST-delivered ACLS. The former group of patients was taken to hospitals that practiced more therapeutic hypothermia, and more percutaneous coronary interventions, which may explain part of the survival benefit and the increase in the number of patients with improved neurological outcome seen with physician-delivered ACLS.

The assessment of neurological outcome in post-cardiac arrest patients is performed variably in those studies that measure it. Although the cerebral performance category is used widely, the measure provides only a gross assessment of functional activity and provides limited information on quality of life. This study raises concerns about the existence of a cohort of severely neurologicallyinjured patients produced by the application of ACLS in the community. This is not supported by previous studies, which have shown generally good quality-of-life scores in the survivors of cardiac arrest at 1 year [5].

The present study adds additional weight to the evidence of the importance of early and effective CPR following cardiac arrest. The impact of bystander CPR on survival was small compared with previous studies [2]; however, it is not clear why this should be the case. No assessment of quality of BCPR was made in the study, and it is not clear what compression-ventilation ratio was in use or whether BCPR was dispatcher assisted. The data for this study were collected between 2005 and 2007; during this period the current compression-ventilation ratio of 30:2 was being introduced.

Rates of spontaneously-delivered bystander CPR are low; approximately two-thirds of patients do not receive CPR prior to the arrival of emergency services [2]. Interventions to increase rates of bystander CPR include the use of dispatcher assistance, where the emergency telephone operator advises the lay rescuer how to perform CPR in real time [6]. This intervention has been demonstrated to increase CPR rates [7] and to increase patient survival following cardiac arrest by about $50 \%$ compared with no CPR [8]. Emphasis is placed increasingly on minimising interruptions to chest compressions as this may improve the success of subsequent defibrillation $[9,10]$.

Previous attempts to demonstrate benefit from prehospital physician-delivered ACLS have produced mixed results. Variation in emergency medical service (EMS) provision between different regions and countries has made it difficult to isolate the impact of physiciandelivered ACLS compared with ELST-delivered ACLS. Comparisons made within individual EMS systems have demonstrated benefit [11], no difference [12], or poorer outcomes [13] following the implementation of physiciandelivered ACLS. Given that many of the therapies available to physicians but not to ELSTs (for example, intubation, central venous catheterisation) are in themselves supported by limited evidence, it is perhaps no surprise that unequivocal evidence for benefit of prehospital physician ACLS is lacking.

The organisation and staffing of emergency medical services remains a decision for appropriate local authorities, because there are many factors that determine the service best suited to each individual environment. The evidence supporting the importance of effective bystander CPR continues to grow, and we must actively encourage and invest in interventions that train competent lay rescuers.

\section{Abbreviations}

ACLS, advanced cardiac life support; BCPR, bystander-initiated

cardiopulmonary resuscitation; CPR, cardiopulmonary resuscitation; ELST, emergency life-saving technician; EMS, emergency medical service.

\section{Competing interests}

The authors declare that they have no competing interests.

\section{Author details}

'Intensive Care Medicine, Royal United Hospital NHS Trust, Bath BA1 3NG, UK. ${ }^{2}$ Anaesthesia and Intensive Care Medicine, Royal United Hospital NHS Trust, Bath BA1 3NG, UK.

Published: 12 January 2011

\section{References}

1. Yasunaga $\mathrm{H}$, Horiguchi $\mathrm{H}$, Tanabe S, Akahane M, Ogawa T, Koike S, Imamura T: Collaborative effects of bystander-initiated cardiopulmonary resuscitation and prehospital advanced cardiac life support by physicians on survival of out-of-hospital cardiac arrest: a nationwide population-based observational study. Crit Care 2010, 14:R199.

2. Sasson C, Rogers MAM, Dahl J, Kellermann AL: Predictors of survival from out-of-hospital cardiac arrest: a systematic review and meta-analysis. Circ Cardiovasc Qual Outcomes 2010, 3:63-81.

3. Koster RW, Baubin MA, Bossaert LL, Caballero A, Cassan P, Castrén M, Granja C, Handley AJ, Monsieurs KG, Perkins GD, Raffay V, Sandroni C: European Resuscitation Council Guidelines for Resuscitation 2010: Section 2. Adult basic life support and use of automated external defibrillators. Resuscitation 2010, 81:1277-1292.

4. Stiell IG, Wells GA, Field ACP, Spaite DW, Nesbitt LP, De Maio, VJ, Nichol G, Cousineau D, Blackburn J, Munkley D, Luinstra-Toohey L, Campeau T, Dagnone E, Lyver M: Advanced cardiac life support in out-of-hospital cardiac arrest. N Engl J Med 2004, 351:647-656.

5. Stiell I, Nichol G, Wells G, De Maio V, Nesbitt L, Blackburn J, Spaite D: Healthrelated quality of life is better for cardiac arrest survivors who received citizen cardiopulmonary resuscitation. Circulation 2003, 108:1939-1944.

6. Hüpfl M, Selig HF, Nagele P: Chest-compression-only versus standard cardiopulmonary resuscitation: a meta-analysis. Lancet 2010, 376:1552-1557.

7. Culley LL, Clark JJ, Eisenberg MS, Larsen MP: Dispatcher-assisted telephone CPR: common delays and time standards for delivery. Ann Emerg Med 1991, 20:362-366.

8. Rea TD, Eisenberg MS, Culley LL, Becker L: Dispatcher-assisted cardiopulmonary resuscitation and survival in cardiac arrest. Circulation 2001, 104:2513-2516

9. Edelson DP, Abella BS, Kramer-Johansen J, Wik L, Myklebust H, Barry AM, Merchant RM, Vanden Hoek TL, Steen PA, Becker LB: Effects of compression depth and pre-shock pauses predict defibrillation failure during cardiac arrest. Resuscitation 2006, 71:137-145.

10. Christenson J, Andrusiek D, Everson-Stewart S, Kudenchuk P, Hostler D, Powell J, Callaway CW, Bishop D, Vaillancourt C, Davis D, Aufderheide TP, Idris A, Stouffer JA, Stiell I, Berg R: Chest compression fraction determines survival in patients with out-of-hospital ventricular fibrillation. Circulation 2009, 120:1241-1247.

11. Soo LH, Gray D, Young T, Huff N, Skene A, Hampton JR: Resuscitation from out-of-hospital cardiac arrest: is survival dependent on who is available at the scene? Heart 1999, 81:47-52. 
12. Olasveengen TM, Lund-Kordahl I, Steen PA, Sunde K: Out-of hospital advanced life support with or without a physician: effects on quality of CPR and outcome. Resuscitation 2009, 80:1248-1252.

13. Yen Z-Shen, Chen Y-Ta, Ko PC-In, Ma MH-Ming, Chen S-Chyr, Chen W-Jone, Lin F-Yue: Cost-effectiveness of different advanced life support providers for victims of out-of-hospital cardiac arrests. J Formosan Med Assoc 2006, 105:1001-1007 doi:10.1186/cc9356

Cite this article as: Jackson RJH, Nolan JP: Improving outcome in out-ofhospital cardiac arrest: impact of bystander cardiopulmonary resuscitation and prehospital physician care. Critical Care 2011, 15:101. 